\title{
Study of Porosity and Voids in Dental Gold Castings
}

\author{
GEORGE P. KELLY \\ University of Michigan School of Dentistry, Ann Arbor, Michigan, USA 48104
}

The problem of voids and porosity has long plagued the dental technician. Many times an otherwise acceptable casting has had to be discarded because voids or porosities have developed within the casting. Because of numerous variables a technician often does not know the cause of the casting failure. Many investigators have studied variables that may affect the occurrence of voids and porosities. $^{1-5}$ Asgar $^{6}$ has conducted a study on the effects of sprue gauge, length, direction, shape, number of sprues, and flaring. He also studied the pressure of the casting machine and the amount of gold used when casting. He found that all of these variables have some effect on the occurrence of voids and porosities. Tucillo and Nielsen ${ }^{7}$ have reported that short, thick sprues tend to minimize local porosity but tend to form surface porosities. They found that the reverse was true with long, thin sprues. Brumfield ${ }^{8}$ recommended inserting a wax rod into the core of the investment when investing the pattern. In this way, gasses could leave the mold cavity in a short time and be free of voids and porosities. Strickland and Sturdevant ${ }^{9}$ say that "back pressure" porosity will be eliminated if a mold temperature of over $1,100 \mathrm{~F}$ is used. They have also found that the type of investment can be important in the elimination of "back pressure" porosity. Strickland and Sturdevant ${ }^{9}$ contend that $^{2}$ varying the temperature of the casting alloy has no effect on "back pressure" porosity.

Sprue size, oven burnout temperature, casting temperature of the gold, presence of a vent or heat sink, and type of investment are among the variables that confront the operator in casting. Small full crowns such as those on premolars are probably the castings most often destroyed by voids and porosities. By making over 200 castings using

Hatton award: 2nd prize, predoctoral division.

This paper is a modified version of the oral presentation of the 48th General Meeting of the IADR. the aforementioned variables, a method for analyzing the problem of voids and porosity in dental gold castings can be shown.

Possible causes of void and porosity occurrence have been sought. Strickland and Sturdevant ${ }^{3}$ claim that "back pressure" porosity occurs because the investment core cannot vent the hot gases fast enough. $O$ 'Brien and Nielsen ${ }^{10}$ have shown that $\mathrm{CaSO}_{4}$ by itself will start to decompose at approximately $2,200 \mathrm{~F}$ into $\mathrm{CaO}$ and $\mathrm{SO}_{2}$. In the presence of carbon, however, this decomposition takes place at a lower temperature $(1300 \mathrm{~F})$ and at a much faster rate. The reaction products here are $\mathrm{CaS}$ and $\mathrm{CO}$. By placing thermocouple wires in the investment the temperature of investment during casting may be determined.

Placing thermocouples within the wax pattern provides a method whereby the process of solidification can be studied. The resulting temperattre curves of the gold at different points in the casting will show where the metal solidifies first and last. With these temperatures, a better understanding of causes of voids and porosity may be found.

\section{Materials and Methods}

The study consisted of two parts. In the first part, castings were made in the usual manner. A wax pattern, which in all instances was identical, was sprued with a single sprue of $5 \mathrm{~mm}$. The pattern was sprued in the center of the occlusal surface. The pattern was then invested using either the hygroscopic or the high heat technic. Burnout occurred at either $900 \mathrm{~F}$ or 1,200 $F$ for one hour. Casting took place with a straight arm centrifugal casting machine (three turns) that contained a gold melting oven. In this manner the temperature of the gold at casting time was recorded. The resultant casting was then checked at the 
pulpal floor surface for suckback and porosity using a $\times 7$ magnification. Porosity and voids were scored as none, slight, moderate, or gross.

Since casting size and shape were not desired as variables, the wax patterns were identical in all instances. In Figure 1 the device used to make these patterns is shown. The die $C$ is placed between the bases $A$ and $B . A$ and $B$ are then connected together. The disk $D$ is placed on top of the bases so that the die protrudes into the hole. A separating agent is then placed in the area where it is needed and molten wax is poured into the hole in the disk. After the wax has hardened, the apparatus is disassembled, and the wax pattern is taken from the die.

The type of pattern used was made in a way to favor void and porosity occurrence, as shown in Figure 2. Long axial walls provide a long channel in which gases must escape from the pulpal floor area during casting. A thick occlusal wall provides a

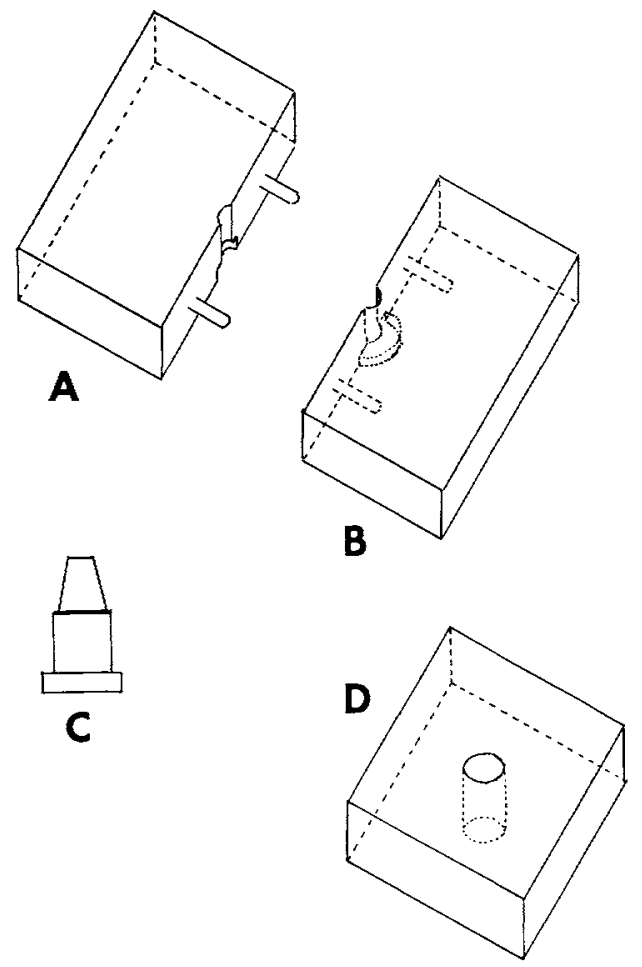

FIg 1.-Apparatus used in making wax patterns. $A$ and $B$, bases; $C$, die; and $D$, disk.

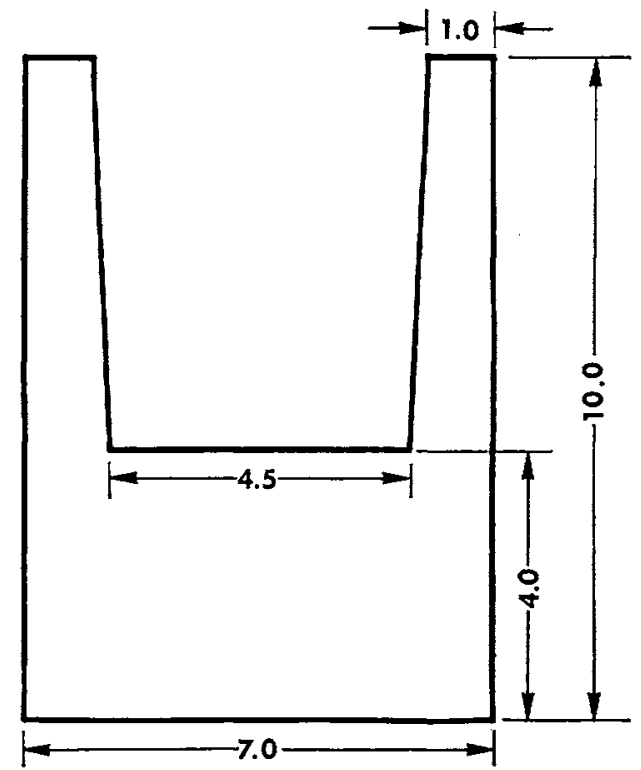

FIG 2.-Cross section of pattern used in experiments.

large volume of molten gold that will contract on solidification. Average axial wall lengths for premolars are about $3 \mathrm{~mm}$. The patterns used had an axial wall length of 6 $\mathrm{mm}$. Average occlusal thickness on premolar full crowns are approximately $2 \mathrm{~mm}$. The occlusal thicknesses of the test patterns were $4 \mathrm{~mm}$.

In the second part of the study, thermocouples were placed in the investment 1.5 $\mathrm{mm} \pm 0.2 \mathrm{~mm}$ from the sprued wax pattern. In Figure 3, $A$ the locations of these thermocouples are shown. The pattern was then hand invested. The thermocouples were connected to a continuous reading $x-y$ recorder. The mold was burned out at either $900 \mathrm{~F}$ or 1,200 $\mathrm{F}$ for one hour. The casting was then made with the centrifugal casting machine. The variation of the temperature with respect to time was recorded during casting. As before, the casting was inspected for voids and porosity with a $\times 7$ magnification and scored appropriately.

Tests were also made with thermocouples placed within the wax pattern and sprue. These locations are shown in Figure $3, B$. The pattern was invested. The thermocouples were attached to an $x-y$ recorder. The casting was made, and the variation of temperature with respect to time was recorded. 

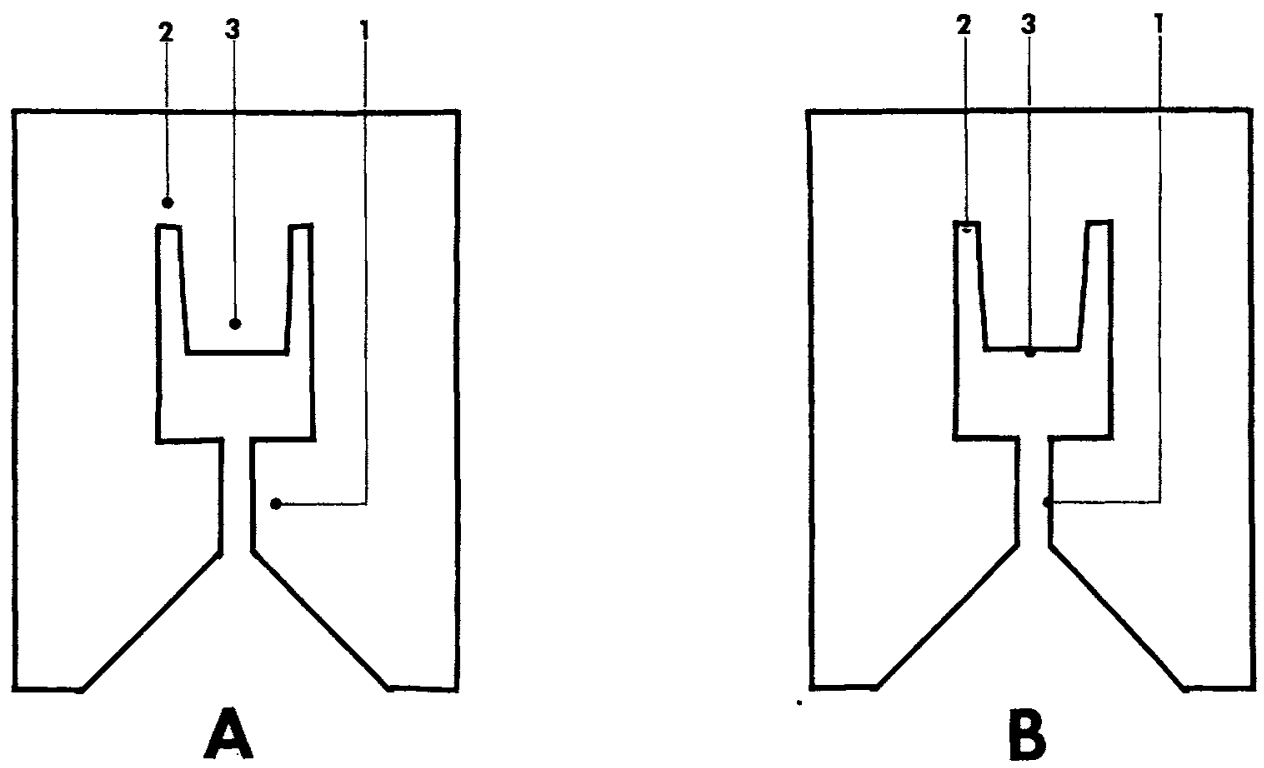

FIG 3.- $A$, location of thermocouples in investment; $B$, location of thermocouples in wax pattern; 1 , sprue; 2 , cervical margin; 3 , pupal floor.

A temperature vs time curve of the molten gold alloy was thus made during the casting process. No attempt was made to score porosity or voids with these specimens.

A schematic drawing of the apparatus used in this experiment is shown in Figure 4. As the casting process was occurring, the thermocouple wire was twisted between the pulley and loop on the casting machine; 20 to 25 seconds elapsed before the wire was bound tightly enough to stop the casting machine. The gold had solidified in all instances by this time. After being connected to a cold junction offset, the circuit was attached in series to a voltage source. With this source a base line for any desired temperature could be used on the graph. The circuit continued into an amplifier and finally was attached to the $x-y$ recorder. The apparatus can be easily calibrated to any

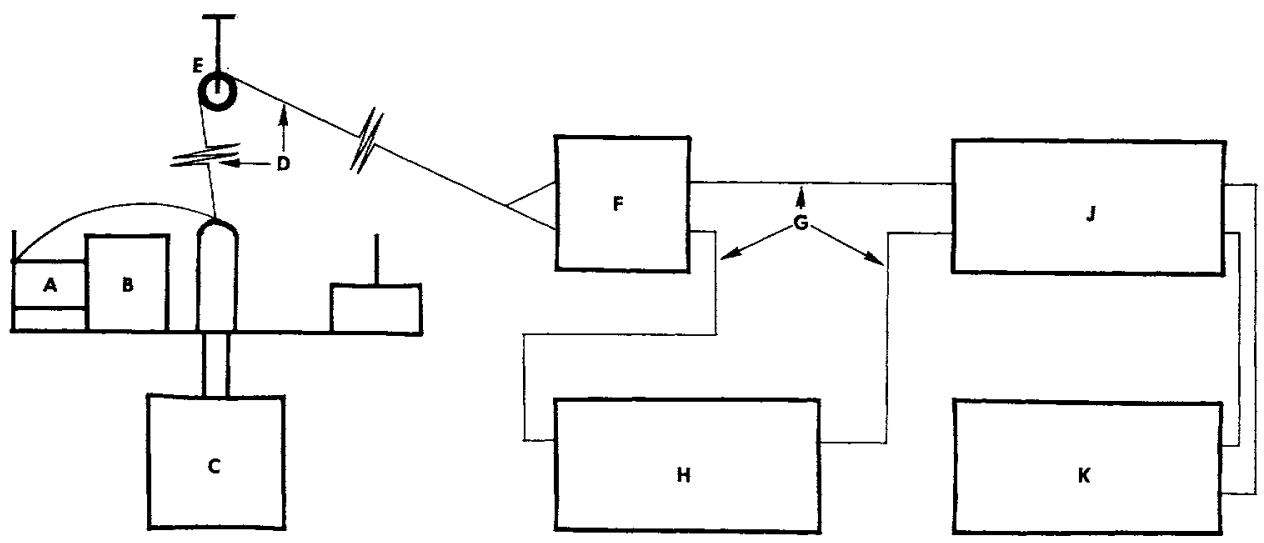

FIG 4.-Schematic drawing of apparatus used for recording temperatures of alloy and investment during casting process. $A$, mold; $B$, muffle; $C$, casting machine; $D$, thermocouple wire; $E$, pulley; $F$, cold junction offset; $G$, copper wire; $H$, voltage source; $J$, amplifier; $K$, recorder. 
desired temperature range with a potentiometer.

Since temperatures below $800 \mathrm{~F}$ are of little or no use in this experiment, the voltage sources were used to adjust the scale reading at no less than $800 \mathrm{~F}$. The voltage source and thermocouples are connected in series so that their electromotive forces (EMF's) oppose each other. As a back EMF, the voltage source acts to adjust the base line to the desired temperature. Chromel and alumel type $K$ thermocouple wire was used. Its useful range $(-300$ to $2300 \mathrm{~F})$ falls well within the temperature range needed. It is relatively inexpensive. Since the wire had to be twisted, long leads and well-insulated yet flexible wire was used. The time constant for the 28 gauge chromel and alumel thermocouple wire used is approximately $\tau=9 \mathrm{msec}$. The time constant is the time in seconds required for $63.2 \%$ of the maximum possible temperature change to be registered. Maximum possible temperature change is the temperature of the object to be measured minus the initial temperature of the probe. Obviously, a thermocouple with a low time constant such as the one used, provides fast response.

\section{Results}

More than 200 castings were made using five variables. These variables included mold burnout temperature, presence of a vent or heat sink, type of investment, sprue size, and casting temperatures of the gold alloy. The conditions of the tests are listed in Table 1. The castings were checked at the pulpal floor surface for voids and porosities using a $\times 7$ magnification. Porosities and voids were scored in one of seven categories:

TABLE 1

Test Conditions

\begin{tabular}{ll}
\hline \multicolumn{1}{c}{ Variable } & Conditions \\
\hline Mold burnout temperature & $900 \mathrm{~F}$ \\
& $1,200 \mathrm{~F}$ \\
Venting & Vent \\
& No vent \\
Investment & Hygroscopic \\
& High heat \\
Sprue size & 11 gauge \\
& 13 gauge \\
& 16 gauge \\
Alloy casting temperature & $1,800 \mathrm{~F}$ \\
& $1,900 \mathrm{~F}$ \\
& $2,100 \mathrm{~F}$ \\
\hline
\end{tabular}

none, slight, moderate, or gross porosities or slight, moderate, or gross voids. Figure $5, A$ is a magnified view of a pulpal floor with no voids or porosities. Castings that had a like appearance were scored as none. Figure $5, B$ is a casting the pulpal floor of which has moderate porosities. Castings that had amounts of porosity greater than Figure $5, A$ but less than Figure 5, $B$ were scored as slight porosity. Figure $5, C$ is a casting with gross porosities. Castings that had amounts of porosity greater than or equal to Figure $5, B$ but less than Figure $5, C$ were scored as moderate porosities. Castings with porosities greater than or equal to Figure $5, C$ but not yet having voids were scored as gross porosities. Castings with voids were also scored as slight, moderate, or gross voids. Figures $5, D$ and $5, E$ show the reference points used to score voids. Figure $5, D$ has a moderate void and Figure $5, E$ has a gross void. All castings were scored in one of these seven categories. The seven ratings were given a number value of zero to six, starting with zero when no voids or porosities were present, and ending with six when gross voids were present. The result of each casting was placed in a table of results. The sum of scores for each condition is shown in Table 2. Four castings were made for each possible set of conditions.

The type of casting made favored porosity and voids. In making a "regular" casting the occurrence of voids and porosity is less frequent. However, if one gets suckback in a dental casting, knowing which variable to change will be of value in eliminating porosities or voids in succeeding castings.

An analysis of variance was made on the results. It was found that the following variables affect suckback and porosity in dental gold castings: mold temperature, venting, type of investment, and sprue size. Mold temperature was found to affect the castings most. This was followed by venting, type of investment, and sprue size, in that order. Temperature at which the metal was cast was shown to have no significant effect on suckback or porosity in the full crown type casting used. Table 3 shows the conditions used and the results obtained. The results for each variable are listed in order of increasing tendency toward porosity and voids. The variables are listed in an order that shows the greatest difference in tendency 

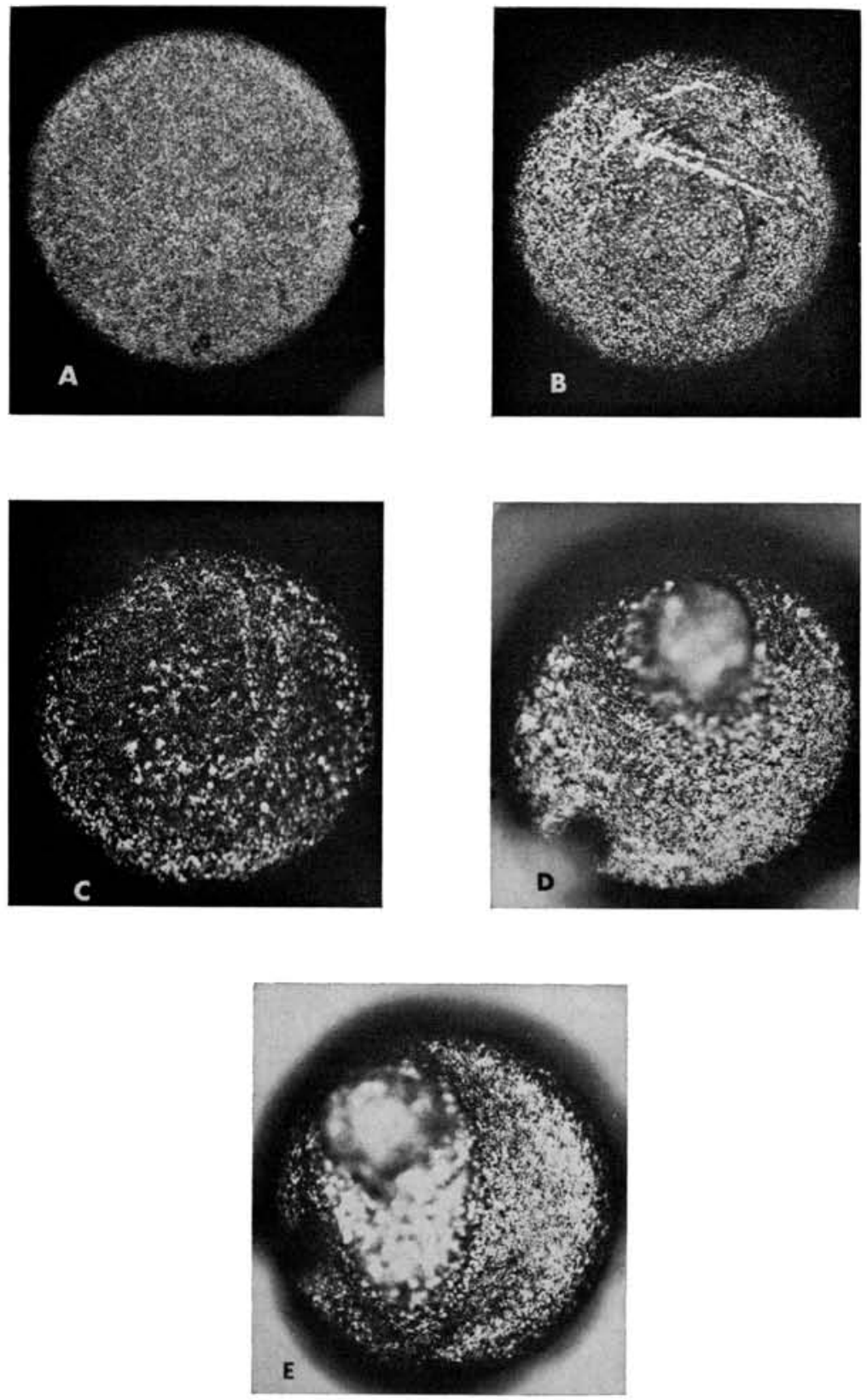

FIg 5.-Pulpal floor region of a casting with $A$, neither voids nor porosities; $B$, moderate porosities; $C$, gross porosities; $D$, a moderate void; and $E$, a gross void.

toward porosities and voids among the results in each variable. In other words, the variables are listed in order of decreasing significance for void and porosity occurrence.

A 1,200 F mold temperature was found to yield less porosity and voids than a burnout temperature of $900 \mathrm{~F}$. Venting produced a better casting than no venting at all. High heat investment reduced porosity and voids in castings when compared with hygroscopic 
TABLE 2

SCORES FOR EACH TEST CONDITION

\begin{tabular}{|c|c|c|c|c|c|c|c|}
\hline \multirow[b]{2}{*}{ Investment } & \multirow{2}{*}{$\begin{array}{c}\text { Casting } \\
\text { Temperature (F) }\end{array}$} & \multicolumn{3}{|c|}{$\begin{array}{l}900 \mathrm{~F}^{*} \\
\text { Sprue Size }\end{array}$} & \multicolumn{3}{|c|}{$\begin{array}{l}1,200 \mathrm{~F}^{*} \\
\text { Sprue Size }\end{array}$} \\
\hline & & 11 & 13 & 16 & 11 & 13 & 16 \\
\hline High heat & $\begin{array}{l}1,800 \\
1,900 \\
2,100\end{array}$ & $\begin{array}{r}11 \\
2 \\
14\end{array}$ & $\begin{array}{l}12 \\
17 \\
19\end{array}$ & $\begin{array}{l}24 \\
23 \\
14\end{array}$ & $\begin{array}{l}0 \\
0 \\
2\end{array}$ & $\begin{array}{l}0 \\
0 \\
3\end{array}$ & $\begin{array}{r}11 \\
4 \\
1\end{array}$ \\
\hline Hygroscopic & $\begin{array}{l}1,800 \\
1,900 \\
2,100\end{array}$ & $\begin{array}{l}23 \\
23 \\
23\end{array}$ & $\begin{array}{l}17 \\
24 \\
24\end{array}$ & $\begin{array}{l}20 \\
23 \\
24\end{array}$ & $\begin{array}{l}0 \\
3 \\
4\end{array}$ & $\begin{array}{r}1 \\
12 \\
5\end{array}$ & $\begin{array}{r}5 \\
10 \\
0\end{array}$ \\
\hline
\end{tabular}

investment. Fewer amounts of porosity and voids were found when using the largest sprue (11 gauge) rather than the smaller sprues (13 and 16 gauge).

In the second part of the study thermocouples were placed in investment approximately $1.5 \mathrm{~mm}$ from the mold cavity to note the temperatures to which the investment rose during casting. The placement of these thermocouples is shown in Figure 3, $A$. A typical graph of time vs temperature of investment during casting is shown in Figure 6. Thermocouples with other wax patterns were placed within the pattern at the cervical margin, pulpal floor, and sprue as shown in Figure 3, $B$ to note metal temperature during casting. A typical graph of time vs temperature of the metal during casting is shown in Figure 7. This graph shows a temperature curve for the metal at each of the areas where the thermocouples were placed.

Thermocouples also act in another manner. In placing them near a casting, they act either as a heat sink or as a vent along which gases may escape. Although there is no conclusive evidence, the theory of a vent is favored. Since the thermocouple wire has an insulated covering of glass braid, it may provide an excellent escape route for contained gases.

Gases in the mold cavity must escape the

TABLE 3

Conditions AND Results

\begin{tabular}{lll}
\hline Mold & & \\
temperature & $1200 \mathrm{~F}$ & $900 \mathrm{~F}$ \\
Venting & Vent & No vent \\
Investment & High heat & Hygroscopic \\
Sprue size & 11 gauge, & 16 gauge \\
Metal & No effect & \\
temperature & & \\
\hline
\end{tabular}

* Mold temperature. mold, or a back pressure will result on the molten gold. If the back pressure is greater than the opposing pressure of the gold entering the mold cavity, porosity, or voids, or both may result. A purpose of the study was to discover if an increase in the metal temperature of the entering gold would significantly raise the temperature of the investment enough to show an increase in porosity or voids. A higher metal temperature might maintain the metal molten for a longer period and might also increase the temperature of the investment enough to produce a greater amount of investment breakdown.

As will be shown later, the molten metal, when cast, starts to solidify in three to four seconds and is solid in five or six seconds after the start of casting. If investment decomposition is to have an effect on suckback and porosity, the decomposition must be within five to six seconds from start of casting. Table 4 lists some maximum temperatures of investment five to six seconds after casting. At four to five seconds these temperatures are about $100 \mathrm{~F}$ less.

Even though the investment gets hot after 15 seconds as seen in Figure 6, we are interested in the area five to six seconds after the start of casting. After this point the gold has solidified. This does not mean that temperature changes may not affect other properties, but it does not affect the occurrence void and porosity.

In studying the results when the thermocouples are in the mold cavity, the order in which the casting solidified can be determined. In knowing the direction of solidification, the possible theories of void and porosity occurrences can be more easily understood. From the results it was shown that solidification started at the cervical margin, progressed toward the pulpal floor, and finally ended in the sprue. 


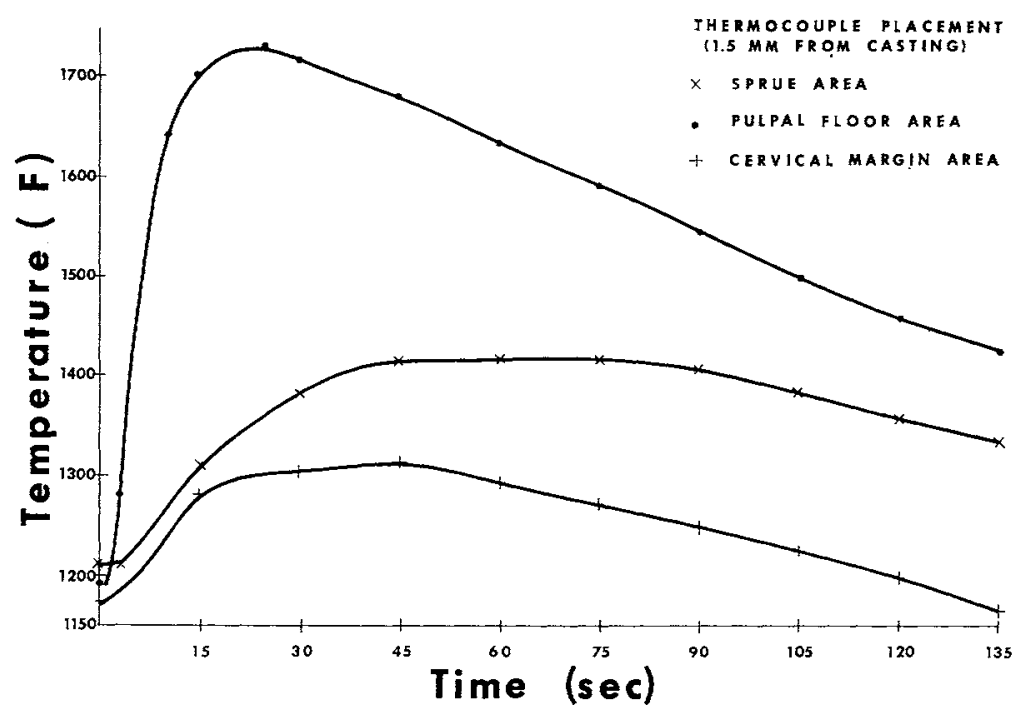

FIG 6.--Temperature curve of investment during casting process $1.5 \mathrm{~mm}$ from the mold cavity in the region of the cervical margin, pulpal floor, and sprue areas.

Figure 7, shows the direction of solidification in casting a metal. When burnout occurred at $900 \mathrm{~F}$ and the metal temperature was approximately $1,910 \mathrm{~F}$, the following results were obtained: The gold at the

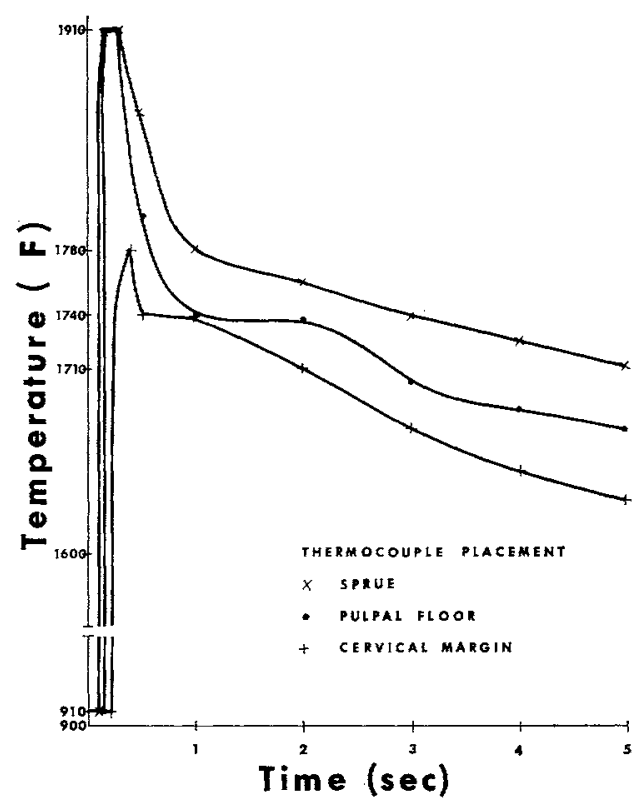

Fig 7.-Temperature curve of gold alloy during casting at the cervical margin, pupal floor, and sprue. cervical margin reached a maximum temperature of $1,780 \mathrm{~F}$. Solidification at the cervical margin started approximately 0.5 seconds after the casting machine was released and had solidified after 2.0 seconds. At 1.0 seconds after the start of casting, the occlusal area started to solidify and continued solidification until 2.8 seconds had passed; 3.0 seconds passed before the sprue started to freeze. It completed solidification after 5.0 seconds. Both the occlusal region and sprue reached a maximum temperature of $1,908 \mathrm{~F}$. The meiting range for the alloy used was 1,710 to $1,740 \mathrm{~F}$. When the mold temperature was $1,200 \mathrm{~F}$ results were comparable to the 900 burnout temperature, except that a longer period of time elapsed before solidification began and during the solidification process (Table 5).

Since the sprue is the last area to solidify, molten metal can continuously feed the mold cavity as the metal solidifies in the

TABLE 4

INVESTMENT TEMPERATURES 5 TO 6 SECONDS AFTER CASTING

\begin{tabular}{ccc}
\hline \multirow{2}{*}{$\begin{array}{c}\text { Metal Temperature } \\
\text { at Start of } \\
\text { Casting (F) }\end{array}$} & \multicolumn{2}{c}{$\begin{array}{c}\text { Temperature of } \\
\text { the Investment }\end{array}$} \\
\cline { 2 - 3 } & $\begin{array}{c}\text { Mold at } \\
900 \mathrm{~F}\end{array}$ & $\begin{array}{c}\text { Mold at } \\
1,200 \mathrm{~F}\end{array}$ \\
\hline 1,800 & 1,375 & 1,515 \\
1,900 & 1,410 & 1,570 \\
2,100 & 1,435 & 1,580 \\
\hline
\end{tabular}


TABLE 5

Solidification of Gold Alloy During Casting

\begin{tabular}{lccc}
\hline & $\begin{array}{c}\text { Solidification Starts } \\
\text { (Seconds) }\end{array}$ & $\begin{array}{c}\text { Solidification Complete } \\
\text { (Seconds) }\end{array}$ \\
\hline Cervical margin & 0.5 & & 2.0 \\
Pulpal floor (occlusal) & 1.0 & $900 \mathrm{~F}$ Burnout & 2.8 \\
Sprue & 3.0 & & 5.0 \\
Cervical margin & 1.3 & & 4.0 \\
Pulpal floor (occlusal) & 1.5 & $1200 \mathrm{~F}$ Burnout & 6.5 \\
Sprue & 5.0 & & 10.5 \\
\hline
\end{tabular}

mold cavity. Because gold shrinks on solidification, it is important that the sprue be the last region to solidify so that it can feed the shrinking metal that will form the needed casting. Other orders of solidification may lead to voids or porosities.

\section{Conclusions}

Under the conditions of this study it has been shown that the following variables significantly affect the amounts of porosity, or voids, or both in dental gold castings: mold temperature, presence of vent, sprue size, and type of investment. Casting temperature of the metal has no significant effect on presence or absence of porosity and voids. Decomposition of the investment during casting due to high temperatures does not significantly affect the occurrence of porosity and voids. Solidification of dental gold castings should start at the cervical margin, progress toward the occlusal surface, and finally finish solidification in the sprue. Other orders of solidification may lead to voids and porosity.

The author thanks the following people for guidance and assistance during the course of this investigation: Kamal Asgar, Edward Dootz, and Edward Tillitson.

\section{References}

1. Shell, J.S., and Hollenback, G.M.: Amount of Compensation for Casting
Shrinkage Required at Different Mold Temperatures, $S$ Calif State Dent Assn Journal 33:11, 1965.

2. Barone, J.: HufF, R.L.; and Dickson, G.: Surface Roughness of Gold Castings, Dent Prog 1:2, 1961.

3. Suffert, L.W., and MAHLER, D.B.: Reproducibility of Gold Casting Made by Present Day Casting Techniques, JADA 50:1, 1955.

4. RYGE, G.; KoZAR, S.F.; and FaIRHURST, C.W.: Porosities in Dental Gold Castings, JADA 54:746-754, 1957.

5. Fusayama, Takao.: Technical Procedure of Precision Casting, J Prosth Dent 9:10371048, 1959.

6. Asgar, K., and Peyton, F.A.: Pits on the Inner Surface of Gold Crowns, $J$ Prosth Dent 9:448-456, 1959.

7. Tuccirlo, J.J., and Nielsen, J.P.: Sprue Design for Cast Gold Alloys, Dent Lab Rev, June-July, 1964.

8. Brumfield, R.C.: How to Vent Full Cast Crown Molds to Avoid Gas Porosity, Thermotrol Technician, March, 1950.

9. STrickiand, W.D., and STURDEVANT, C.M.: Porosity in the Full Cast Crown, JADA 58:69-78, 1959.

10. O'Brien, W.J., and Nielsen, J.P.: Decomposition of Gypsum Investment in the Presence of Carbon, $J$ Dent Res 38:541$547,1959$. 